\title{
Minimal Invasive Treatment in Pelvic-Ureteric Junction Obstruction: A Comprehensive Review
}

\author{
Irfan Wahyudi $\mathbb{D}^{1,2}$ \\ William Tendi $\mathbb{D}^{1,2}$ \\ Fakhri Rahman (1D) \\ Gerhard Reinaldi \\ Situmorang $\mathbb{D}^{1,2}$ \\ Arry Rodjani $\mathbb{D}^{1,2}$
}

'Department of Urology, Dr. Cipto Mangunkusumo Hospital, Jakarta, Indonesia; ${ }^{2}$ Faculty of Medicine,

Universitas Indonesia, Jakarta, Indonesia
Correspondence: Irfan Wahyudi Department of Urology, Dr. Cipto Mangunkusumo Hospital, Jakarta, Indonesia

Tel +62 2I 3152892

Fax +62213145592

Email irf_wahyudi@yahoo.co.id

\begin{abstract}
Pelvic-ureteric junction obstruction (PUJO) is a common condition, and one of the lead causes of hydronephrosis in children. Currently, the gold standard treatment of PUJO is open surgery using the Anderson-Hynes-modified dismembered pyeloplasty technique. However, with the advancement of medical technology, several minimal invasive approaches were developed, including endoscopic, laparoscopic, and robotic approach, from which the best choice of surgical technique was yet to be determined. Considering the advantages and disadvantages of these methods, the recommended option is to tailor the best surgical approach to each individual patient, and to the surgeons' preference and experience. Considering these recent advances, a new algorithm is proposed to choose the best minimal invasive modalities invasive treatment to treat PUJO.
\end{abstract}

Keywords: Anderson-Hynes dismembered pyeloplasty, hydronephrosis, minimal invasive, PUJO

\section{Introduction}

Pelvic-ureteric junction obstruction (PUJO) is a condition in which urine flow disruption occurs between kidney pelvis and proximal ureter. PUJO is identified in 1:500 live birth, with male to female ratio of 2:1. ${ }^{1,2}$ PUJO is considered as the most common cause of congenital hydronephrosis. Nevertheless, it could also manifest or develop (acquired) later during adult life. ${ }^{3,4}$ Despite various experiments and research, the exact etiology and pathogenesis of PUJO is still unknown. ${ }^{5}$ On the other hand, the underlying cause of an acquired PUJO is relatively clearer. Acquired PUJO is associated with abnormalities of intrinsic factor, such as ureteral wall scarring, or the presence of external factor, such as retroperitoneal mass or fibrosis. If left untreated, this condition could potentially lead to kidney interstitial fibrosis which causes impairment of kidney function, and negatively impacts patient's quality of life. ${ }^{6,7}$ Therefore, the ultimate goal of any intervention in PUJO cases is to preserve kidney function. ${ }^{8}$

Although surgery is associated with a high success rate, not all PUJO cases require surgical intervention. Better understanding of the natural history and progression of PUJO has helped us select patients' sub-groups, who will benefit most from surgery. The European Association of Urology (EAU) guidelines recommends surgery as the treatment of choice in symptomatic PUJO patients. Other indications to perform surgery include impairment in split renal function $(<40 \%)$, a $>10 \%$ decrease of split renal function in subsequent studies, poor drainage function after diuretic administration, increased anteroposterior diameter on ultrasound and grade 
III or IV hydronephrosis as defined by the Society for Fetal Urology (SFU). ${ }^{2}$ Nevertheless, these indications may vary across different centres, and should always be tailored to the patients' individual condition.

The role of surgery in PUJO management was first established by Trendelenburg, who performed the first reconstructive surgery for PUJO in 1886. Since then, various techniques have been introduced, including the Anderson-Hynes-modified dismembered pyeloplasty, which is regarded as the gold standard surgery for PUJO surgery. ${ }^{8,9}$ However, with the advancement of medical technology, the practice of open surgery in urology has been largely replaced by minimal invasive surgery. Currently, neither open nor the minimal invasive surgery was recommended as the best strategy for PUJO treatment in any guidelines available. This article aimed to provide a comprehensive review of minimally invasive techniques currently available for PUJO treatment.

\section{PUJO Management: A Brief Historical Review}

In 1949, Anderson and Hynes described open dismembered pyeloplasty technique to correct PUJO. ${ }^{10}$ This technique has been shown to be very versatile, safe and effective, resulting in $95 \%$ success rate. ${ }^{11,12}$ To date, the same technique is still regarded as gold standard for pyeloplasty, especially in infants younger than 1 year. Other open reconstruction techniques have also been reported by various authors, mainly describing non-dismembered pyeloplasty techniques, such as Foley YV pyeloplasty, CulpDeWeerd Spiral Flap, Scardino-Prince Vertical Flap, or Davis intubated ureterotomy. ${ }^{12}$

The role of minimally invasive surgery in PUJO treatment was introduced by Wickham and Kellet in 1983, and Arthur Smith in 1984 using endopyelotomy technique. ${ }^{13}$ However, this technique has been reported to be less effective than conventional dismembered pyeloplasty. In 1990s, Schuessler et al. and Peters et al. pioneered the laparoscopic approach in performing dismembered pyeloplasty. ${ }^{10}$ The most recent development in PUJO surgical management is percutaneous endopyeloplasty and robotic surgery, which were first introduced in 2002. ${ }^{14,15}$ The historical development of PUJO treatment is summarised in Figure 1, and will be discussed in more detail under subsequent headings.

\section{Minimal Invasive Treatment in PUJO \\ Endoscopic Surgery}

Endoscopic approach for PUJO was commonly recognised as the treatment of choice in adult patients due to its minimal invasion and low morbidity. ${ }^{4}$ This approach may incorporate endopyelotomy or endopyeloplasty technique. In endopyelotomy, a lateral or posterolateral incision is performed. The incision should be made full thickness to reveal periureteric fat tissue. This method is considered to be less invasive, requires less operating time and shorter duration of hospital stay. In some centres, endopyelotomy is performed in an outpatient basis. The overall success rate of endopyelotomy is $73-90 \%$. The procedure was reported to be especially useful in cases where the stenosis length is less than $2 \mathrm{~cm}$, or without significant hydronephrosis, or when renal function is more than $25 \%{ }^{13}$ In addition, endopyelotomy was also preferred in PUJO patients with concomitant stone disease. ${ }^{16}$ A study by Kartal et al. revealed that patients with single renal stone sized less than $2 \mathrm{~cm}$, stricture less than $1 \mathrm{~cm}$, and primary PUJO could be safely treated with retrograde laser endopyelotomy, followed by retrograde intrarenal surgery. ${ }^{17}$

Endopyelotomy could be performed in either antegrade or retrograde approach. A study by Bautista et al. evaluating five patients with PUJO concluded that antegrade endopyelotomy using a micro-percutaneous approach showed satisfactory outcome after a mean follow up of 36 months. ${ }^{18}$ Another study by Dobry et al. found that antegrade endoscopic approach had the lower need of analgesic and complication rate compared to open pyeloplasty. However, the success rate was also found to be lower in antegrade approach $(80 \%$ vs $98 \%$ in open pyeloplasty). ${ }^{19}$ Various factors have been associated with
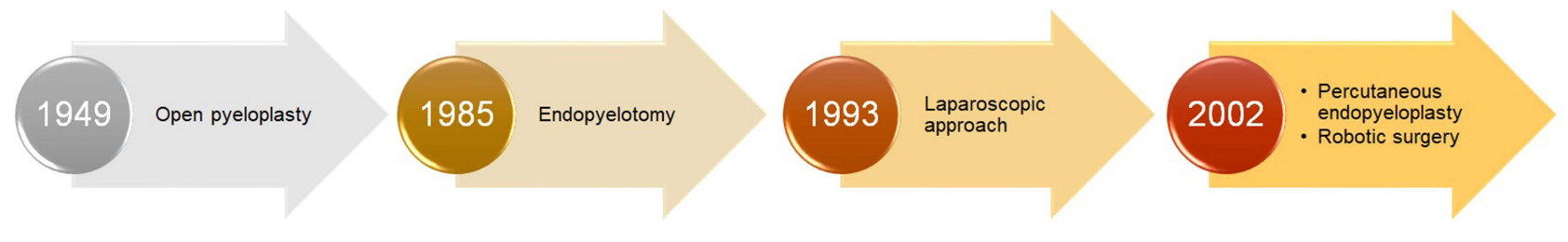

Figure I Historical development of pelvic-ureteric junction obstruction treatment. 
endopyelotomy failure, including the presence of crossing vessel. A technique described by Alotaibi in 2018 was proposed to overcome the difficulty related to the presence of crossing vessels. The author combined the use of retrograde access to establish a percutaneous tract for antegrade nephroscope access. Initial incision was then made to the ureteropelvic junction to create a window for retropelvic space access. Introduction of the nephroscope through this window allowed visualisation of potential crossing vessels, which will be coagulated if small, or avoided if larger in caliber. ${ }^{20}$ Current recommendation does not recommend endopyelotomy to be repeated once it failed. ${ }^{13}$

Retrograde is a popular approach in performing endopyelotomy, which is also found to be more cost-effective. Silva et al. described that the equipments necessary in retrograde endopyelotomy could be manually made using copper wire. The outcome of using this equipment were found to be similar to using other more sophisticated retrograde modalities. In addition, this simple technology was also found to be suitable for smaller caliber ureterorenoscope sheath. $^{21}$

The literatures described numerous ways to perform endopyelotomy using retrograde approach, such as simple dilatation with balloon, incision with laser, and incision using an Acucise ${ }^{\circledR}$ or cutting balloon. ${ }^{16}$ A case report by Umekawa et al. observed a satisfactory result in a 6-yearold girl with symptomatic PUJO treated with endoscopic surgery in retrograde fashion using Acucise. ${ }^{22}$ In addition, the success rate of Acucise endopyelotomy ranged between $45 \%$ and $77 \%{ }^{23}$

There were only a number of studies directly comparing antegrade to retrograde approaches in endoscopic surgery. Minervini et al. observed that retrograde approach was associated with lower complication rate, shorter length of hospital stay, and a higher success rate compared to the antegrade approach. ${ }^{24}$ On the other hand, a study by Chow et al. stated that both antegrade and retrograde approach had similar success rate. ${ }^{25}$ Possible reasons for such discrepancies is different follow-up time between the two studies. It is likely that the study by Minervini et al. included failures detected during later follow-up period. It is important to note that both papers only included adult patients in their study population. The only available research that compared the two approaches, which included paediatric patients in its study population was performed by Lam et al. in 2003. Unfortunately, the population of the study included both paediatric and adult patients and the results of the study were not age- adjusted. Hence, it was difficult to conclude whether patients' age has any impact on the safety and effectiveness of antegrade and retrograde endopyelotomies. Overall, the author described that there was no difference in success rate between antegrade and retrograde approach (81.3\% vs $75.9 \%$, respectively). However, antegrade approach was proven to be significantly more effective in patients with severe hydronephrosis, whilst the retrograde approach was associated with shorter operative time and hospital stay. $^{26}$

In endopyeloplasty, an additional horizontal suturing procedure was incorporated to the standard longitudinal endopyelotomy incision through a nephroscope. This procedure requires longer operating time, more advance equipments, and more experience. However, the success rate of this procedure is considerably higher than endopyelotomy alone and the outcome was reported to be similar to laparoscopic dismembered pyeloplasty (up to $100 \%){ }^{13,27}$ Currently, an antegrade approach is the only method used to perform endopyeloplasty.

Despite increasing interest in endoscopic surgical management of PUJO, many comparative trials had shown that in terms of outcome, the endoscopic surgery was inferior to laparoscopic pyeloplasty. ${ }^{16}$ A study by Jacobs et al. revealed that the failure rate of endopyelotomy was higher than laparoscopic or robotic approach. ${ }^{28}$ From a cost analysis perspective, the same author reported that endoscopic approach has the lowest cost compared to other surgical interventions for PUJO. Interestingly, the report claimed that the cost of both open surgery and laparoscopic or robotic surgery did not differ significantly. This was mainly attributable to the significantly shorter hospital stay in the laparoscopic and robotic group. Therefore, it is essential to carefully assess and inform patients for potential comorbidities, which may prolong postoperative hospital stay. $^{29}$

\section{Laparoscopic Surgery}

Generally, current evidence suggests that the success rate of laparoscopic pyeloplasty ranges from $94 \%$ to $97 \%$. $^{30,31}$ Laparoscopic pyeloplasty can be performed using a retroperitoneal or transperitoneal approach, depending on the surgeon's preference and experience. To date, there is no evidence to suggest that the two approaches differ significantly with regard to operating time and overall success rate. Both dismembered and non-dismembered pyeloplasty can be performed laparoscopically. A study by Rassweiler et al. in 2018 showed that the success rate of 
the laparoscopic YV pyeloplasty was 90\%, slightly higher when compared to $89 \%$ success rate of Anderson-Hynes laparoscopic pyeloplasty. ${ }^{32}$ Similar result was also observed in the study by Subotic et al. in 2013. Although the difference reported was not statistically significant, the study showed that YV retroperitoneoscopic pyeloplasty had a higher success rate than the typical AndersonHynes technique $(90.5 \%$ vs $85 \%){ }^{33}$ The result of both studies showed that non-dismembered pyeloplasty, especially the YV technique, may be considered to replace the Anderson-Hynes technique, which was long suggested as the primary choice when performing pyeloplasty. However, it is important to consider that the number of studies directly comparing YV to Anderson-Hynes is scarce; thus, it is currently difficult to conclude the superiority of one technique over the other. The advantage of laparoscopic procedure compared to endoscopy is the ability to treat PUJO with high ureteral insertion, complete luminal obliteration, severe hydronephrosis and crossing vessel. ${ }^{13,34}$ In addition, laparoscopic pyeloplasty resulted in a similar success rate in PUJO cases with concomitant anomalies found in children, such as horseshoe kidney, pelvic kidney, or duplex collecting system. ${ }^{35}$ However, this depends greatly on the experience of the surgeon. ${ }^{13}$ A meta-analysis by Uhlig et al. showed that laparoscopic pyeloplasty had a lower complication rate and a similar success rate, but a longer operating time compared to open pyeloplasty. $^{14}$

The introduction of single-port surgery in laparoscopy pyeloplasty was first described in 2007. This procedure reduced the common surgical-site related complications such as bleeding and infection, with a better cosmetic result. ${ }^{10}$ Stein et al. and Tugcu et al. observed that laparoendoscopic single-site surgery (LESS) provided excellent satisfaction for patients in terms of wound scars. ${ }^{36,37}$ Nonetheless, the lack of triangulation in LESS may lead to clashing of the instruments. Furthermore, manipulating many instruments through a single port is proven to be more challenging, thus prolonging the learning curve. To overcome this issue, other techniques were developed, such as the combination of open pyeloplasty and LESS (hybrid LESS). This technique was reported to be effective in paediatric population. Hybrid LESS incorporated the advantage of LESS procedure to put a sterile atraumatic cord around the ureter and draw it out through the single port. This allowed subsequent ureteropyeloplasty to be performed extracorporeally. A study by Dhao et al. revealed that the hybrid LESS was associated with a shorter operating time and length of hospital stay than open pyeloplasty and conventional LESS procedure. ${ }^{38}$ Another technique utilising the LESS principle is the single-incision triangulated umbilical surgery (SITUS), which combines the classic laparoscopy principles with the minimal invasiveness of LESS. ${ }^{10}$ Liu et al. observed that the single-port system LESS had a similar success rate, postoperative complication and length of hospital stay to conventional multi-port procedure. However, the operating time was significantly shorter using the multi-port laparoscopy. The scar assessment was better using the multi-port laparoscopy. ${ }^{39}$ Another comparison was made by Xu et al. The study compared laparoscopic pyeloplasty with balloon dilatation. The result showed that laparoscopic pyeloplasty was associated with a higher success rate than balloon dilatation (95.5\% vs $71 \%$, respectively). ${ }^{40}$

In 2004, a hybrid technique named one-trocar-assisted pyeloplasty (OTAP) was developed by El Ghoary. This technique was considered as the ideal approach for surgeons during their early acquisitioning step of laparoscopic pyeloplasty and was regarded as a useful option in cases with crossing vessels. The technique was performed by approaching the renal pelvis anteriorly using a $10 \mathrm{~mm}$ operative telescope via a $12 \mathrm{~mm}$ flank incision. The approach was made retroperitonally, followed by exteriorising the uretero-pelvic junction and performing dismembered pyeloplasty extra-corporeally. ${ }^{41}$ The success rate in this technique was up to $91 \%$. An interesting modification of this technique was later performed by Pace et al. in 2019. Instead of using the classic flank incision, the authors performed a posterior incision just lateral to the sacrospinous muscle to reach the ureteropelvic junction posteriorly. This approach allowed a rapid exposure of the kidney because of the less tissue thickness compared to the flank incision. ${ }^{42}$

\section{Robotic Surgery}

The use of robotic system in laparoscopy surgery was initiated by the introduction of the Da Vinci robotic system, which was approved by the Food and Drug Administration in July 2000. Furthermore, the introduction of the Single Port system which allowed a full $360^{\circ}$ rotation of the robotic arm around the cannula raised even more interest. ${ }^{43}$ Surgical precision and extended maneuverability provided by the robotic system were amongst the main advantages of this approach, which facilitated better dissection, thus reducing blood loss and increasing suture quality. ${ }^{44}$ In addition, with a success 
rate ranging from $94 \%$ to $100 \%$, robotic pyeloplasty was also effective in children underwent secondary pyeloplasty and complex procedure such as in ureterocalicostomy for recurrent PUJO or intrarenal uretero-pelvic junction. ${ }^{45}$ Oderda et al. observed that robotic surgery was an excellent choice in treating PUJO patients complicated with horseshoe kidney in both paediatric and adult patients. ${ }^{46}$ A recent systematic review by Masieri et al. also showed that the reduction of hydronephrosis was reported in $96 \%$ paediatric patients who underwent robotic redo pyeloplasty. ${ }^{47}$ The only disadvantage of robotic surgery was the higher cost when compared to the conventional open pyeloplasty. However, as mentioned previously, the shorter hospital stay associated with robotic pyeloplasty may favour its use and balance the cost it endures. ${ }^{11}$ Boysen et al. described another way to reduce the cost of robotic surgery by using renal ultrasound complimented with diuretic renal scan instead of the more expensive retrograde studies as the pre-operative imaging modality. The authors explained that a proper interpretation of these diagnostic tools may reduce overall costs and radiation exposure when preparing patients to undergo robotic surgery. ${ }^{48}$
Robotic pyeloplasty is mostly utilised for older children. However, some studies comparing the efficacy of open and robotic pyeloplasty in infants also reported similar outcome, with better aesthetic and less pain in the group undergoing robotic pyeloplasty. ${ }^{11,49}$ The review by Boysen et al. also stated that robotic approach in infants was safe and effective. ${ }^{48}$ The summary of advantages and disadvantages of minimal invasive approach in PUJO treatment is summarised in Table 1.

Robotic pyeloplasty was especially appealing due to its shorter learning curve. This is especially useful for surgeons without prior experience of performing standard laparoscopic pyeloplasty. ${ }^{10,50} \mathrm{~A}$ report has shown that many surgeons prefer to perform robotic pyeloplasty due to the shorter learning curve than laparoscopy, its ability to reduce tremor and better ergonomics. ${ }^{11}$ Esposito et al. found that anastomotic time in robotic surgery was significantly shorter than laparoscopic approach (79 min vs 105.5 min, respectively) with comparable success rate (96.7\% and $100 \%$, respectively). ${ }^{51}$ Similar results were also observed by Zhang et al., who studied the operative time and mean hospital stay of both modalities. The authors concluded that all parameters including success

Table I Advantages and Disadvantages of Pelvic-Ureteric Junction Obstruction Minimal Invasive Treatment

\begin{tabular}{|c|c|c|c|}
\hline Approach & Techniques & Advantages & Disadvantages \\
\hline \multirow[t]{2}{*}{ Endoscopy } & Endopyelotomy & $\begin{array}{l}\text { - Less invasive } \\
\text { - Shorter operating time } \\
\text { - Shorter length of hospital stay } \\
\text { - Could be performed in outpatient setting }\end{array}$ & $\begin{array}{l}\text { - Not recommended in failed } \\
\text { endopyelotomy } \\
\text { - Less effective in the presence of } \\
\text { crossing vessel } \\
\text { - Radiation exposure }\end{array}$ \\
\hline & Endopyeloplasty & - Higher functional success than endopyelotomy & $\begin{array}{l}\text { - Longer operating time } \\
\text { - Longer learning curve } \\
\text { - Radiation exposure }\end{array}$ \\
\hline \multirow[t]{2}{*}{ Laparoscopy } & Conventional & $\begin{array}{l}\text { - Better efficacy in unfavorable conditions (high ureteral insertion, } \\
\text { complete luminal obliteration, severe hydronephrosis, or crossing } \\
\text { vessel) } \\
\text { - Less complication }\end{array}$ & $\begin{array}{l}\text { - Longer operating time } \\
\text { - Need vast experience }\end{array}$ \\
\hline & $\begin{array}{l}\text { Laparoendoscopic } \\
\text { single site (LESS) }\end{array}$ & $\begin{array}{l}\text { - Shorter operating time compared to conventional laparoscopy } \\
\text { - Better cosmetic result }\end{array}$ & $\begin{array}{l}\text { - Prone to instrument clashing } \\
\text { - Longer learning curve }\end{array}$ \\
\hline \multicolumn{2}{|c|}{ Robotic surgery } & $\begin{array}{l}\text { - Shorter learning curve } \\
\text { - Less tremor } \\
\text { - Better ergonomics } \\
\text { - Shorter length of hospital stay } \\
\text { - Better cosmetic result } \\
\text { - Less complication } \\
\text { - Similar efficacy in young infant }\end{array}$ & - Might be more costly \\
\hline
\end{tabular}


rate was comparable in both groups. ${ }^{52}$ Hong et al. described that there was a significantly shorter operative time in robotic surgery than laparoscopy. However, the result found in this study may due to the fact that the study was conducted in two different centers with different surgical teams. ${ }^{53}$

A recent meta-analysis suggested that robotic pyeloplasty had a significantly higher success rate and less operating time than endoscopic procedures to treat PUJO. When compared to laparoscopy procedure, robotic surgery also had a significantly higher success rate (ranged between $78 \%$ and $100 \%) .{ }^{14,54}$ Furthermore, Silay et al. observed that robotic surgery was associated with significantly less postoperative complication compared to laparoscopic surgery
(3.2\% vs $7.7 \%$, respectively). This was further confirmed by Taktak et al., who also reported with a shorter hospital stay in the robotic pyeloplasty group. ${ }^{55}$

Taking into accounts the potential benefits of all surgical modalities available in treating PUJO, we proposed an algorithm to select the most suitable minimally invasive treatment for PUJO correction (Figure 2). In this algorithm, we proposed that all paediatric patients should be considered to undergo laparoscopic or robotic surgery, depending on the hospital resources and surgeon's experience and preference. In patients with a concomitant renal stone, endoscopic approach can be considered despite offering a lower success rate. The same principle applied to the adult population, where laparoscopic and robotic approach should be

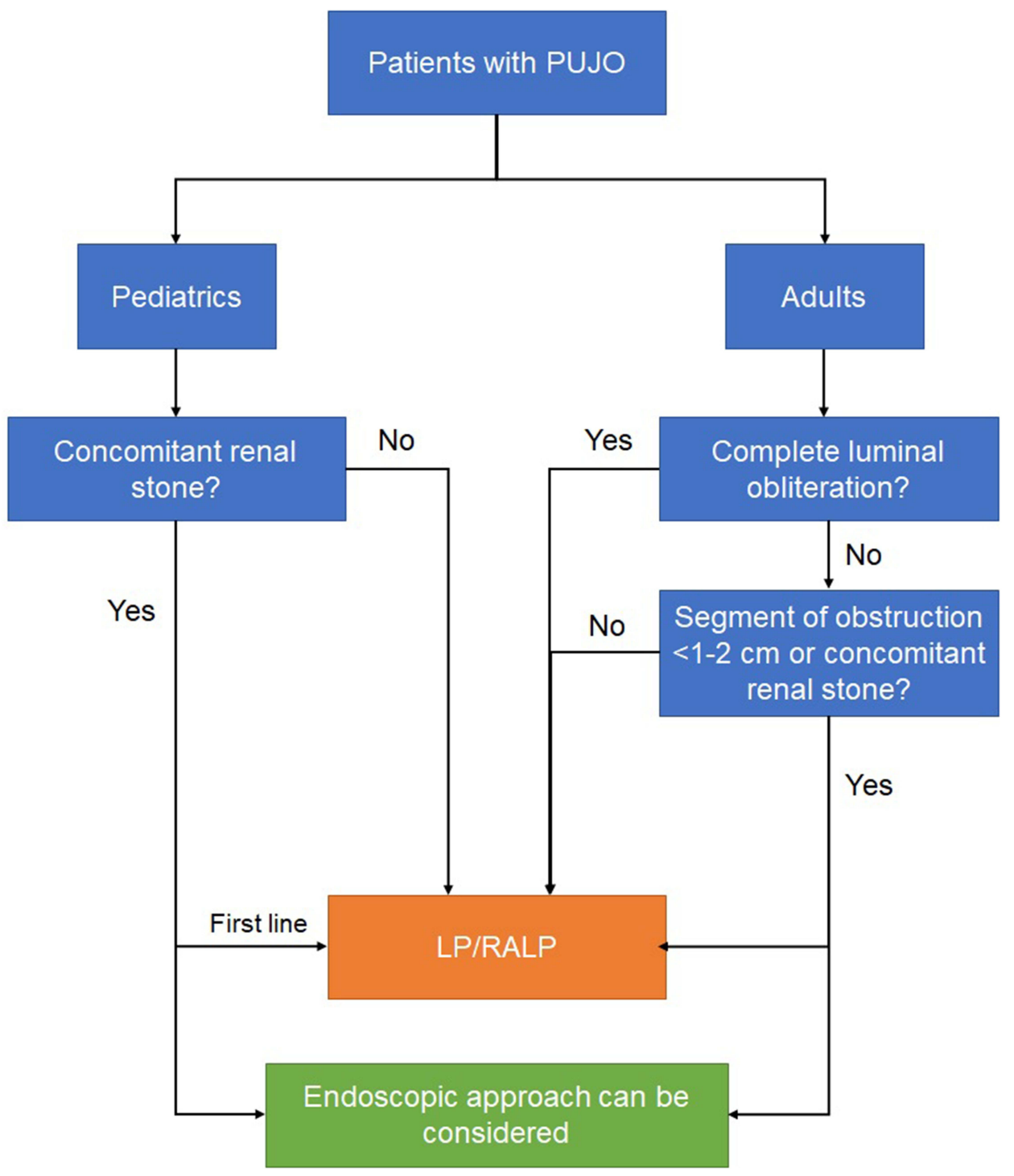

Figure 2 Recommended algorithm in pelvic-ureteric junction minimal invasive management.

Abbreviations: PUJO, pelvic-ureteric junction management; LP, laparoscopic pyeloplasty; RALP, robotic-assisted laparoscopic pyeloplasty. 
recommended as the first-line treatment. Endoscopic surgery can be considered in the presence of urinary stone or in short ureteral stenosis $(<2 \mathrm{~cm})$, and incomplete obliteration of the obstructed ureteral segment. Open pyeloplasty should be offered in places where minimally invasive resources were unavailable, or when the surgeons' experience to perform these minimally invasive interventions were limited.

\section{Conclusion}

Currently available evidence showed that the success rate of both robotic and laparoscopic surgery in the management of PUJO is comparable. Endoscopic approach to manage PUJO in paediatric cases has a higher failure rate compared to open or laparoscopic or robotic approaches. However, endoscopy could be offered in certain clinical scenarios. Robotic surgery has offered a significant technical advantage, which ensured a high success rate and low post-operative complication rate, with a relatively shorter learning curve. The decision to choose the best surgical technique to correct PUJO should be tailored to the patient's individual condition, surgeon's preference, and available resources.

\section{Disclosure}

The authors declare that there is no conflict of interest to disclose.

\section{References}

1. Termos S, AlKabbani M, Ulinski T, et al. Ureteropelvic junction obstruction and parathyroid adenoma: coincidence or link? Case Reports Nephrol. 2017;2017:1-4. doi:10.1155/2017/9852912

2. Radmayr C, Bogaert G, Dogan HS, et al. EAU Guidelines on Paediatric Urology. The Netherlands: EAU Guidelines Office; 2020.

3. Jackson L, Woodward M, Coward RJ. The molecular biology of pelvi-ureteric junction obstruction. Pediatr Nephrol. 2018;33 (4):553-571. doi:10.1007/s00467-017-3629-0

4. Grasso M, Caruso RP, Phillips CK. UPJ obstruction in the adult population: are crossing vessels significant? Rev Urol. 2001;3 (1):42-51

5. Avanoglu A, Tiryaki S. Embryology and morphological (Mal) development of UPJ. Front Pediatr. 2020;8:7-9. doi:10.3389/ fped.2020.00137

6. Kefale B, Alebachew M, Tadesse Y, Engidawork E. Quality of life and its predictors among patients with chronic kidney disease: a hospital-based cross sectional study. PLoS One. 2019;14(2):1-16. doi:10.1371/journal.pone. 0212184

7. Chevalier RL. Congenital urinary tract obstruction: the long view. $A d v$ Chronic Kidney Dis. 2015;22(4):312-319. doi:10.1053/j. ackd.2015.01.012

8. Hashim H, Woodhouse CRJ. Ureteropelvic junction obstruction. Eur Urol Suppl. 2012;11(2):25-32. doi:10.1016/j.eursup.2012.01.004

9. Kausik S, Segura JW. Surgical management of ureteropelvic junction obstruction in adults. Int Braz J Urol. 2003;29(1):3-10. doi:10.1590/ S1677-55382003000100002
10. Mendrek M, Vogeli TA, Bach C. Recent advances in urologic surgical techniques for pyeloplasty (Version 1). F1000Res. 2019;8:F1000 Faculty Rev-295. doi:10.12688/f1000research.15866.1

11. Passoni NM, Peters CA. Managing ureteropelvic junction obstruction in the young infant. Front Pediatr. 2020;8:242. doi:10.3389/ fped.2020.00242

12. Partin AW, Dmochowski RR, Kavoussi LR, Peters CA. CampbellWalsh-Wein Urology. 12th ed. Philadelphia, PA: Elsevier, Inc.; 2021.

13. Shawky A, Bastawisy MG, Ramadan AR, Ahmed S. Pyeloplasty the dilemma: open - endoscopic - or laparoscopic? Clin Surg. 2018;3:1934.

14. Desai MM, Gill IS, Carvalhal EF, et al. Percutaneous endopyeloplasty: a novel technique. $J$ Endourol. 2002;16(7):431-443. doi: $10.1089 / 089277902760367377$

15. Uhlig A, Uhlig J, Trojan L, Hinterthaner M, von Hammerstein-equord A, Strauss A. Surgical approaches for treatment of ureteropelvic junction obstruction - a systematic review and network meta-analysis. BMC Urol. 2019;19:112. doi:10.1186/s12894-019-0544-7

16. Strother MC, Mucksavage P. Minimally invasive techniques for the management of adult UPJ obstruction. Curr Urol Rep. 2016;17(5):39. doi:10.1007/s11934-016-0593-3

17. Kartal I, Tuygun C, Karakoyunlu AN, Sandikci F, Baylan B, Ersoy H. Retrograde intrarenal surgery following laser endopyelotomy; sequential procedures for ureteropelvic junction obstruction and nephrolithiasis. Urol J. 2019;16(6):541-546.

18. Fernández-Bautista B, Parente A, Ortiz R, Burgos L, Angulo JM. Micropercutaneous endopyelotomy for the treatment of secondary ureteropelvic junction obstruction in children. $J$ Pediatr Urol. 2020;16(5):687.e1-687.e4. doi:10.1016/j.jpurol.2020.08.004

19. Dobry E, Usai P, Studer UE, Danuser H. Is antegrade endopyelotomy really less invasive than open pyeloplasty? Urol Int. 2007;79 (2):152-156. doi:10.1159/000106330

20. Alotaibi KM. Percutaneous retropelvic endopyelotomy for treatment of ureteropelvic junction obstruction. Urol Ann. 2018;10(4):358-362. doi:10.4103/UA.UA_61_18

21. Silva EG, Rabaça CC, Figueiredo AC, Sousa JA, Morgado ET. Retrograde endopyelotomy using an original home-made diathermy probe. $J$ Endourol. 2000;14(9):731-733. doi:10.1089/ end.2000.14.731

22. Umekawa $T$, Ishikawa $Y$, Kajikawa $H$, Iguchi $M$, Kurita $T$. A pediatric case of ureteropelvic junction obstruction treated with retrograde endopyelotomy. Hinyokika Kiyo. 1996;42(11):895-898.

23. Khan F, Ahmed K, Lee N, Challacombe B, Khan MS, Dasgupta P. Management of ureteropelvic junction obstruction in adults. Nat Rev Urol. 2014;11(11):629-638. doi:10.1038/nrurol.2014.240

24. Minervini A, Davenport K, Keeley FX Jr, Timoney AG. Antegrade versus retrograde endopyelotomy for pelvi-ureteric junction (PUJ) obstruction. Eur Urol. 2006;49(3):536-542; discussion 542-543. doi:10.1016/j.eururo.2005.11.025

25. Chow GK, Geisinger MA, Streem SB. Endopyelotomy outcome as a function of high versus dependent ureteral insertion. Urology. 1999;54(6):999-1002. doi:10.1016/S0090-4295(99)00306-4

26. Lam JS, Cooper KL, Greene TD, Gupta M. Impact of hydronephrosis and renal function on treatment outcome: antegrade versus retrograde endopyelotomy. Urology. 2003;61(6):1107-1111. doi:10.1016/S00904295(03)00231-0

27. Symons SJ, Palit V, Biyani CS, Cartledge JJ, Browning AJ, Joyce AD. Minimally invasive surgical options for ureteropelvic junction obstruction: a significant step in the right direction. Indian J Urol. 2009;25(1):27-33. doi:10.4103/0970-1591.45533

28. Jacobs BL, Lai JC, Seelam R, et al. Urologic diseases in America project. the comparative effectiveness of treatments for ureteropelvic junction obstruction. Urology. 2018;111:72-77. doi:10.1016/j. urology.2017.09.002

29. Jacobs BL, Seelam R, Lai JC, et al. Cost analysis of treatments for ureteropelvic junction obstruction. J Endourol. 2017;31(2):204-209. doi:10.1089/end.2016.0722 
30. Gadelmoula M, Abdel-Kader MS, Shalaby M, et al. Laparoscopic versus open pyeloplasty: a multi-institutional prospective study. Cent European J Urol. 2018;71(3):342-345.

31. Chiancone F, Fedelini M, Pucci L, Meccariello C, Fedelini P. Laparoscopic management of recurrent ureteropelvic junction obstruction following pyeloplasty: a single surgical team experience with 38 cases. Int Braz J Urol. 2017;43(3):512-517. doi:10.1590/ s1677-5538.ibju.2016.0198

32. Rassweiler J, Klein J, Goezen AS. Retroperitoneal laparoscopic non-dismembered pyeloplasty for uretero-pelvic junction obstruction due to crossing vessels: a matched-paired analysis and review of literature. Asian J Urol. 2018;5(3):172-181. doi:10.1016/j. ajur.2018.03.001

33. Subotic S, Weiss H, Wyler S, et al. Dismembered and non-dismembered retroperitoneoscopic pyeloplasty for the treatment of ureteropelvic junction obstruction in children. World $J$ Urol. 2013;31(3):689-695. doi:10.1007/s00345-012-0887-0

34. Panek W, Jong TPVM, Szydełko T, Chrzan R. Management of crossing vessels in children and adults: a multi-center experience with the transperitoneal laparoscopic approach. Adv Clin Exp Med. 2019;28 (6):777-782. doi:10.17219/acem/94142

35. Brunhara JA, Moscardi PRM, Mello MF, et al. Transperitoneal laparoscopic pyeloplasty in children: does upper urinary tract anomalies affect surgical outcomes? Int Braz J Urol. 2018;44(2):370-377. doi:10.1590/s1677-5538.ibju.2017.0224

36. Stein RJ, Berger AK, Brandina R, et al. Laparoendoscopic single-site pyeloplasty: a comparison with the standard laparoscopic technique. BJU Int $\quad 2011 ; 107(5): 811-815 . \quad$ doi:10.1111/j.1464410X.2010.09558.x

37. Tugcu V, Ilbey YO, Sonmezay E, et al. Laparoendoscopic single-site versus conventional transperitoneal laparoscopic pyeloplasty: a prospective randomized study. Int J Urol. 2013;20(11):1112-1117. doi:10.1111/iju.12126

38. Dhaou MB, Zouari M, Ammar S, Zitouni H, Jallouli M, Mhiri R. Hybrid laparoendoscopic single-site (LESS) pyeloplasty: initial experience in children. Prog Urol. 2017;27(2):87-92. doi:10.1016/j. purol.2016.12.005

39. Liu D, Zhou H, Ma L, et al. Transumbilical multi-port laparoscopic pyeloplasty versus transumbilical single-site laparoscopic pyeloplasty for ureteropelvic junction obstruction in children: a retrospectively comparative study. J Pediatr Urol. 2017;13(6):618.e1-618.e5. doi:10.1016/j.jpurol.2017.05.009

40. Xu N, Chen SH, Xue XY, et al. Comparison of retrograde balloon dilatation and laparoscopic pyeloplasty for treatment of ureteropelvic junction obstruction: results of a 2-year follow-up. PLoS One. 2016;11(3):e0152463. doi:10.1371/journal.pone.0152463

41. Turrà F, Escolino M, Farina A, Settimi A, Esposito C, Varlet F. Pyeloplasty techniques using minimally invasive surgery (MIS) in pediatric patients. Transl Pediatr. 2016;5(4):251-255. doi:10.21037/ tp.2016.10.05

42. Di Pace MR, Tripi D, Sergio M, Lima M, Cimador M. Posterior one-trocar-assisted pyeloplasty. J Ped Endosc Surg. 2019;1(1):33-36. doi:10.1007/s42804-019-00009-w
43. Dirie NI, Ahmed MA, Wang S. Is secondary robotic pyeloplasty safe and effective as primary robotic pyeloplasty? A systematic review and meta-analysis. J Robot Surg. 2020;14(2):241-248. doi:10.1007/ s11701-019-00997-0

44. Diana P, Casale P, Saita AR, Lughezzani G, Buffi N. Ureteropelvic junction obstruction: robot-assisted pyeloplasty. In: Kucuk S, Canda AE, editors. Medical Robotics - New Achievements. IntechOpen; 2020.

45. Bilgutay AN, Kirsch AJ. Robotic ureteral reconstruction in the pediatric population. Front Pediatr. 2019;22(7):85. doi:10.3389/ fped.2019.00085

46. Oderda M, Calleris G, Allasia M, et al. Robot-assisted laparoscopic pyeloplasty in a pediatric patient with horseshoe kidney: surgical technique and review of the literature. Urologia. 2017;84(1):55-60. doi:10.5301/uro.5000188

47. Masieri L, Sforza S, Grosso AA, et al. Robot-assisted laparoscopic pyeloplasty in children: a systematic review. Minerva Urol Nefrol. 2020;72(6):673-690. doi:10.23736/S0393-2249.20.03854-0

48. Boysen WR, Gundeti MS. Robot-assisted laparoscopic pyeloplasty in the pediatric population: a review of technique, outcomes, complications, and special considerations in infants. Pediatr Surg Int. 2017;33 (9):925-935. doi:10.1007/s00383-017-4082-7

49. Kawal T, Srinivasan AK, Shrivastava D, et al. Pediatric robotic-assisted laparoscopic pyeloplasty: does age matter? J Pediatr Urol. 2018;14(6):540.e1-540.e6. doi:10.1016/j. jpurol.2018.04.023

50. Naitoh Y, Ajiki J, Yamada Y, Fujihara A, Hongo F, Ukimura O. Comparison of the initial operative experience of a single surgeon carrying out robot-assisted laparoscopic pyeloplasty, laparoendoscopic single-site pyeloplasty and conventional laparoscopic pyeloplasty. Int J Urol. 2020;27(2):186-187. doi:10.1111/iju.14150

51. Esposito C, Masieri L, Castagnetti M, et al. Robot-assisted vs laparoscopic pyeloplasty in children with uretero-pelvic junction obstruction (UPJO): technical considerations and results. J Pediatr Urol. 2019;15(6):667.e1-667.e8. doi:10.1016/j.jpurol.2019.09.018

52. Zhang Y, Ouyang W, Xu H, et al. Secondary management for recurrent ureteropelvic junction obstruction after pyeloplasty: a comparison of re-do robot-assisted laparoscopic pyeloplasty and conventional laparoscopic pyeloplasty. Urol Int. 2019;103 (4):466-472. doi:10.1159/000503156

53. Hong P, Ding G, Zhu D, et al. Head-to-head comparison of modified laparoscopic pyeloplasty and robot-assisted pyeloplasty for ureteropelvic junction obstruction in China. Urol Int. 2018;101(3):337-344. doi:10.1159/000492337

54. Morales-López RA, Pérez-Marchán M, Pérez Brayfield M. Current concepts in pediatric robotic assisted pyeloplasty. Front Pediatr. 2019;7:4. doi:10.3389/fped.2019.00004

55. Taktak S, Llewellyn O, Aboelsoud M, Hajibandeh S, Hajibandeh S. Robot-assisted laparoscopic pyeloplasty versus laparoscopic pyeloplasty for pelvi-ureteric junction obstruction in the paediatric population: a systematic review and meta-analysis. Ther Adv Urol. 2019;22 (11): 1756287219835704 .
Research and Reports in Urology

\section{Publish your work in this journal}

Research and Reports in Urology is an international, peer-reviewed, open access journal publishing original research, reports, editorials, reviews and commentaries on all aspects of adult and pediatric urology in the clinic and laboratory including the following topics: Pathology, pathophysiology of urological disease; Investigation and treatment of urological disease; Pharmacology of drugs used for the treatment of urological disease. The manuscript management system is completely online and includes a very quick and fair peer-review system, which is all easy to use. Visit http://www.dovepress.com/ testimonials.php to read real quotes from published authors. 